\title{
Supercapacitor Nanofiber Electrodes Graphene-Based
}

\author{
Mustafa H. Mustafa ${ }^{*}$, Alan Zdunek \\ University of Illinois at Chicago, Department of Mechanical, Chemical Engineering (MC 110), 842 \\ West Taylor Street, Chicago, IL 60607-7022 \\ *Email: mmusta4@gmail.com, zdunek@uic.edu
}

doi: $10.20964 / 2017.04 .22$

Received: 5 September 2016 / Accepted: 6 January 2017 / Published: 12 March 2017

Carbon-based polyacrylonitrile (PAN) nanofiber mats formed via the electrospinning process with varying amounts of graphene and carbon black were used as electrodes in single cell supercapacitor experiments in $1 \mathrm{M} \mathrm{H}_{2} \mathrm{SO}_{4}$. A strong influence of initial electrospinning mixture concentration on capacitance and electrode structure was observed. Electrodes fabricated from a lower carbon mixture containing PAN and graphene showed the highest capacitances whereas electrodes fabricated from higher carbon mixtures of PAN, graphene and carbon black had significantly lower capacitance values. Transmission electron microscope (TEM) images show an amorphous carbon structure for electrodes with the highest capacitance value whereas a turbostratic structure was more prevalent for the lower capacitance supercapacitors.

Keywords: Supercapacitor; Nanofiber; Electrode; Graphene; Electrospinning

\section{$\underline{\text { FULL TEXT }}$}

(C) 2017 The Authors. Published by ESG (www.electrochemsci.org). This article is an open access article distributed under the terms and conditions of the Creative Commons Attribution license (http://creativecommons.org/licenses/by/4.0/). 